\title{
ORIGEM E TRANSFORMAÇÃO DOS NÚCLEOS URBANOS DAS CIDADES DE QUATÁ E PARAGUAÇU PAULISTA
}

\author{
Mariana Guimarães Marchezi Chaves, Arlete Maria Francisco
}

Universidade Estadual Paulista - UNESP, Curso Arquitetura e Urbanismo, Presidente Prudente, SP. E-mail: maariana chaves@hotmail.com. Agência de fomento: CNPq.

\section{RESUMO}

A implantação da ferrovia no estado de São Paulo permitiu a exploração e ocupação de áreas despovoadas. Na região da Alta Sorocabana, a estrada de ferro possibilitou a formação de núcleos urbanos, a partir das estações. Esta pesquisa estudou duas cidades, Quatá e Paraguaçu Paulista, que surgiram neste contexto e apresentam características comuns em sua formação. O objetivo foi realizar a análise morfológica e compreender a lógica de formação dos núcleos urbanos. A metodologia se definiu baseada em Panerai (2006) e Lamas (1993), focada no estudo do tecido urbano e seus elementos formadores, utilizando bibliografia e documentação disponível sobre as cidades e trabalho de campo. Concluiu-se que o traçado dessas cidades obedeceu ao tabuleiro de xadrez e se organizou a partir da estação e ferrovia. Observou-se que não houve preocupação estética e urbanística na implantação desses traçados, que se preservam, enquanto a principal modificação foi a ocupação da esplanada.

Palavras-chave: Desenho Urbano, Estrada de Ferro Sorocabana, Quatá, Paraguaçu Paulista.

\section{ORIGIN AND TRANSFORMATION OF THE URBAN CORE OF QUATÁ AND PARAGUAÇU PAULISTA CITIES.}

\begin{abstract}
The implantation of the railroad in the state of São Paulo allowed the exploration and occupation of unpopulated areas. In the region of Alta Sorocabana, the railway gave rise to urban cores from its stations. This research studied two cities, Quatá and Paraguaçu Paulista, which emerged in this context and have common characteristics in its formation. The aim was to accomplish morphological analysis and understand the logic of the urban cores formation. The methodology was defined based on Panerai (2006) and Lamas (1993), focused on the study of the urban tissue and its forming elements, using bibliography and documentation available about the cities and fieldwork. It was concluded that these cities followed the standard in chessboard and was organized from the station and railway. It was observed that there was no aesthetics and urbanistic concern in these layouts implantation, which are preserved, while the main modification was the esplanade occupation.
\end{abstract}

Keywords: Urban Design, Sorocabana Railway, Quatá, Paraguaçu Paulista.

\section{INTRODUÇÃO}

A implantação da ferrovia no estado de São Paulo, que teve início na década de 1860, permitiu a exploração e ocupação de regiões até então despovoadas. Com o desenvolvimento da ferrovia, surgiram novas empresas ferroviárias, entre elas a Estrada de Ferro Sorocabana, que possibilitou a formação de novos núcleos urbanos, além do transporte de produtos e da própria população, incentivando a ocupação do extremo oeste do estado de São Paulo, já que servia como meio de transporte para que os compradores de terras conhecessem a região. (ABREU, 1972; FRANCISCO, 2017).

Na região da Alta Sorocabana, a chegada da ferrovia originou os núcleos urbanos, a partir das suas estações, que permitiam a chegada da população. A pesquisa realizou o estudo de duas destas cidades, Quatá e Paraguaçu Paulista, após já ter estudado outras duas cidades, Martinópolis e Indiana, que surgiram a partir da implantação da Estrada de Ferro Sorocabana na região do 
Oeste Paulista. Dessa forma, estas cidades apresentam características comuns em seu processo de formação urbana.

O objetivo do estudo foi realizar a análise morfológica das cidades e investigar a origem dos seus núcleos urbanos, dando continuidade à pesquisa anterior. Como objetivos específicos, identificar os autores da produção do núcleo urbano e as transformações ocorridas nos traçados originais; sistematizar o conjunto de informações iconográficas e documentais dos traçados originais das cidades.

\section{METODOLOGIA}

Os estudos foram realizados a partir do método de análise morfológica, se baseando em Lamas (1993) e Panerai (2006). A morfologia urbana estuda o tecido urbano e seus elementos formadores, a fim de compreender a lógica de formação da cidade. Para tanto, utilizou-se bibliografia disponível sobre as cidades em estudo; documentação disponível no Arquivo Público do Estado, no Instituto Geográfico e Cartográfico e no Escritório da Inventariança da Rede Ferroviária Federal S.A. em São Paulo, além de trabalho de campo.

A análise foi feita através do estudo dos mapas da cidade, antigos e mais recentes, observando os elementos morfológicos, como, o traçado, o parcelamento, o crescimento, entre outros, e a relação entre eles, além de esquemas gráficos. Os mapas e desenhos foram refeitos utilizando o software AutoCad, a partir dos quais as leituras foram realizadas.

\section{RESULTADOS}

Paraguaçu Paulista tem suas origens históricas na área onde, atualmente, localiza-se o distrito de Conceição de Monte Alegre, considerada a "semente" da cidade. Esta foi uma das cidades que o pioneiro José Teodoro de Souza estabeleceu, após ter assinado o termo de posse em 1856, servindo de base para a penetração da região e para os negócios de compra e venda das terras (FRANCISCO, 2015). Entretanto, os trilhos da ferrovia não passaram por Conceição de Monte Alegre e esta permaneceu isolada, tornando-se, mais tarde, distrito de Paragraçu Paulista.

Em 1915, foi iniciada a construção da primeira estação de Paraguaçu Paulista, que começou a funcionar no ano seguinte, em 1916, com o nome de "Paraguassu", denominação dada pela diretoria da estrada de ferro, que a cidade adotou posteriormente, com a grafia "ç". A partir da estação é que o novo loteamento é aberto, por Domingos Paulino Vieira, conhecido na cidade como Minguta. Em 1948, passa a ser denominada Paraguaçu Paulista (AMPUDIA, 2016; IBGE, 2016; PARAGUAÇU PAULISTA, 2016).

Através da análise de mapas antigos de Paraguaçu Paulista encontrados no Arquivo Público do Estado de São Paulo deduziu-se qual seria o perímetro do núcleo urbano original (Figura 1), foi possível observar que o desenho segue o padrão do traçado em tabuleiro de xadrez e que possui quadras de $88 \times 88$ metros.

Figura 1. Núcleo Urbano Original de Paraguaçu Paulista.
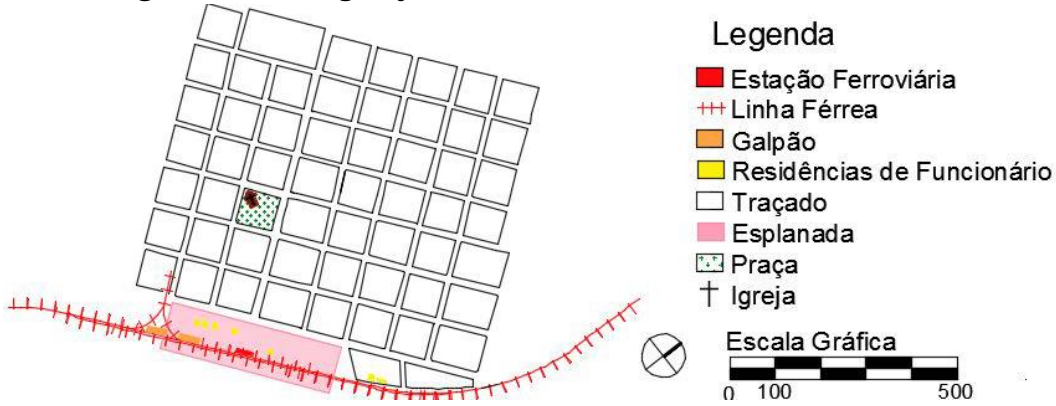

Fonte: Planta da Cidade de Paraguassú, sem data, fornecida pelo Arquivo Público do Estado de São Paulo, redesenhado pela Autora.

Paraguaçu Paulista repetiu a malha ortogonal em seu crescimento no entorno do núcleo urbano original, houve também a ocupação da área "além linha", área posterior a estação e linha férrea, que não reproduziu o desenho inicial do núcleo. Em suas expansões mais recentes, o traçado ortogonal ainda se mantém em alguns pontos, mas em locais distantes da área central há uma mudança nesse desenho, observa-se que a tipologia das quadras se modifica nesses pontos mais afastados (Figura 2). 
Figura 2. Esquema de Crescimento de Paraguaçu Paulista.

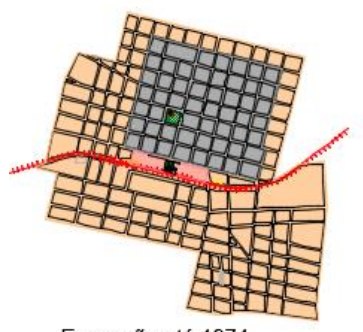

Expansão até 1974

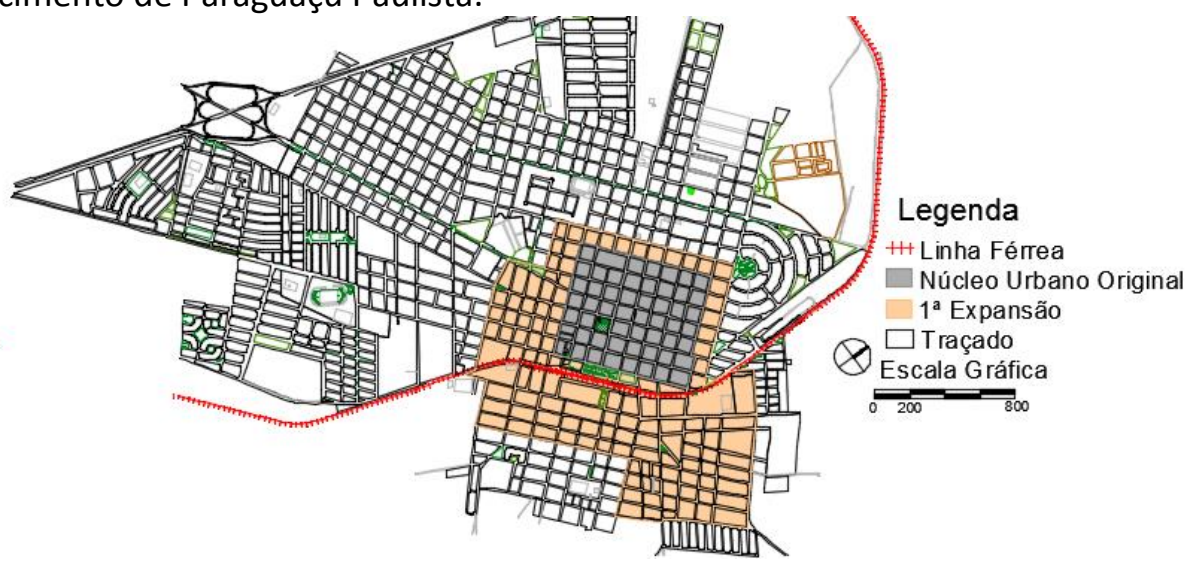

Fonte: Planta da Cidade de Paraguassú, s/data, fornecida pelo Arquivo Público do Estado de São Paulo e de Paraguaçu Paulista, 2016, fornecida pela Prefeitura Municipal de Paraguaçu Paulista (PMPP), redesenhado pela Autora.

A esplanada corresponde a um grande retângulo localizado no entorno da estação ferroviária e suas dimensões variavam de acordo com a cidade. Sua área garantia espaço para a localização de outras construções da ferrovia, como casas e armazéns e, além disso, foi um elemento importante para o desenho urbano dos núcleos originados a partir da linha férrea (CHAVES, 2017).
A esplanada da Estação de Paraguaçu Paulista era ocupada inicialmente pela estação ferroviária, algumas residências de funcionários da ferrovia e galpões da companhia Estrada de Ferro Sorocabana (Figura 3).

Figura 3. Esplanada de Paraguaçu Paulista, década de 1940.
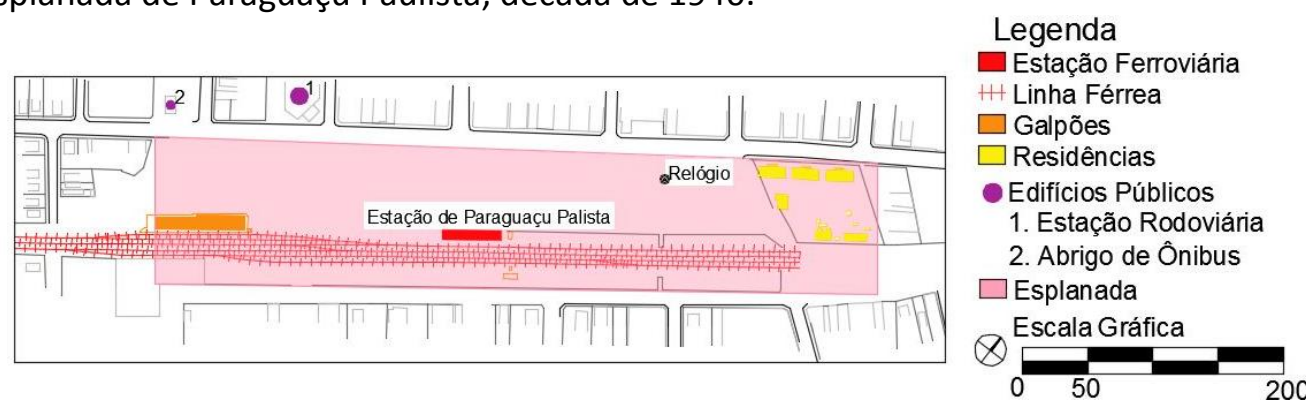

Fonte: Patio de Paragraçu, década de 1940, fornecida pelo Escritório da Inventariança da Rede Ferroviária Federal S.A. de São Paulo, redesenhado pela Autora.

Atualmente, a esplanada está ocupada por uma praça em frente à estação, um jardim, denominado Jardim das Cerejeiras, que compõem um dos atrativos turísticos da cidade, e algumas bancas de comércio localizadas em outra praça, ao lado da rodoviária. Os galpões da ferrovia e a estação foram mantidos (Figura 4). A estação ferroviária, hoje, abriga a guarda municipal e uma delegacia e corresponde ao ponto de partida do passeio da Maria Fumaça.

Figura 4. Esplanada de Paraguaçu Paulista, 2017.
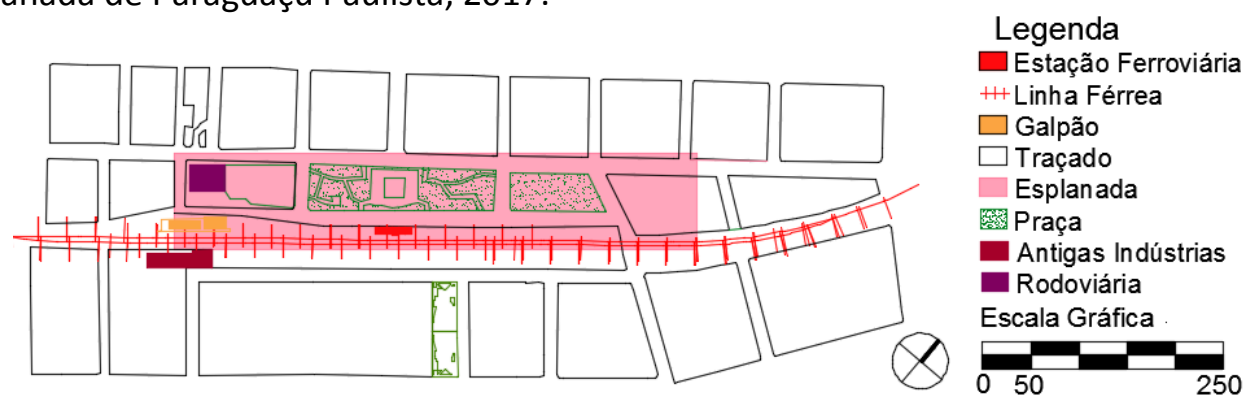

Fonte: Planta de Paraguaçu Paulista, 2016, fornecida pela PMPP e trabalho de campo, redesenhado pela Autora. 
A partir da análise das quadras do núcleo urbano original, através de um mapa do Arquivo Público do Estado de São Paulo, de 1941, deduziu-se uma tipologia da divisão da quadra em lotes (Figura 5). Ghirardello (1997) apresentou essa mesma tipologia como a usual no início do século $\mathrm{XX}$, com dimensão de $88 \times 88$ metros.

Figura 5. Tipologia possível das quadras de Paraguaçu Paulista.

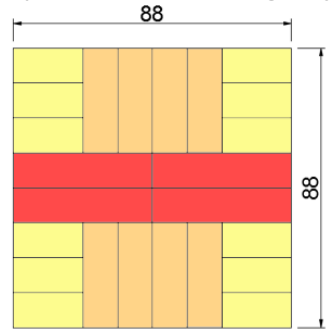

Lote de $11 \times 22$ metros

Lote de $11 \times 33$ metros

Lote de $11 \times 44$ metros

Fonte: Planta da cidade de Paraguaçu, 1941, fornecida pelo Arquivo Público do Estado de São Paulo e Paraguaçu Paulista, 2016, analisado e redesenhado pela Autora.

A colonização da cidade de Quatá teve êxito também quando a linha férrea foi aberta ao tráfego em 1916, ano em que o plano de partilha das terras da região foi aprovado, após a instalação da Fazenda Paulo Barreto e a abertura da Fazenda Santa Lina. O patrimônio de Quatá foi demarcado em 1922 por Bruno Giovanetti, com seu loteamento feito na área entre a linha do trem e a rua Monte-Alvão, considerada um limite do traçado da cidade (ENCICLOPÉDIA, 2003; QUATÁ, 2016). A cidade adotou o nome da estação ferroviária, Quatá, que foi dado devido ao som do macaco-bugio comum na região.
O núcleo urbano original da cidade foi identificado a partir da análise dos mapas obtidos no Arquivo Público de São Paulo e, com isso, foi elaborado seu redesenho (Figura 6). Algumas quadras apresentam formato triangular e outras retangulares com menor dimensão, respeitando o limite territorial imposto pela rua Monte-Alvão, que dava continuidade a uma estrada presente no local. $O$ arruamento inicial respeitou a delimitação dessa via, o que indica a presença desta antes da implantação do núcleo urbano.

Figura 6. Núcleo Urbano Original de Quatá.

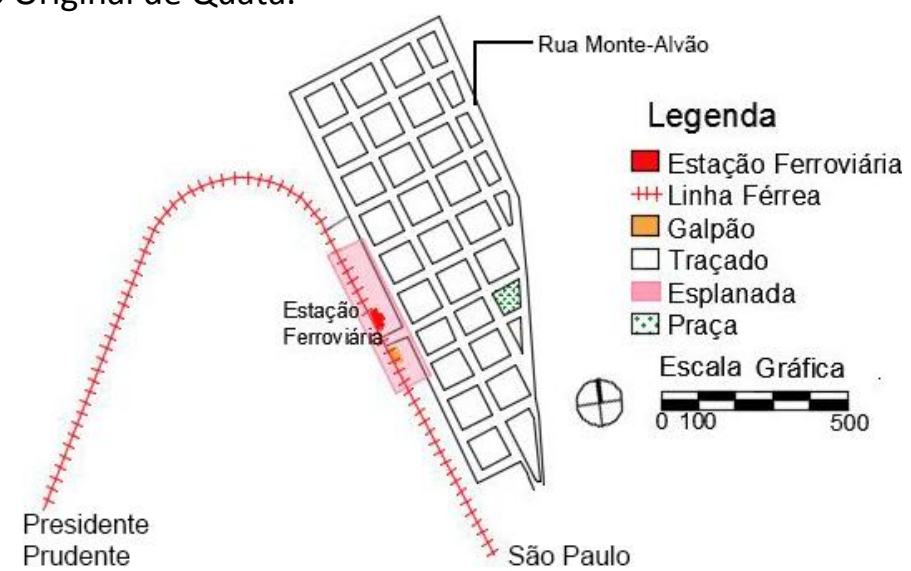

Fonte: Planta Geral de Quatá, 1935, fornecida pelo Arquivo Público do Estado de São Paulo, redesenhado pela Autora.

Quatá não cresceu no entorno de seu primeiro loteamento de forma radial, esse crescimento não seguiu a quadrícula, poucas quadras foram implantadas seguindo o desenho inicial, já seu crescimento mais recente foi espraiado, com diferentes loteamentos introduzindo outros padrões de arruamento, quadras e lotes na cidade, dessa forma, apenas o traçado do núcleo original apresenta a regularidade do tabuleiro de xadrez. Essa expansão que a cidade sofreu não ocupou as áreas além do limite da rua Monte-Alvão (Figura 7). 
Figura 7. Esquema de Crescimento de Quatá.
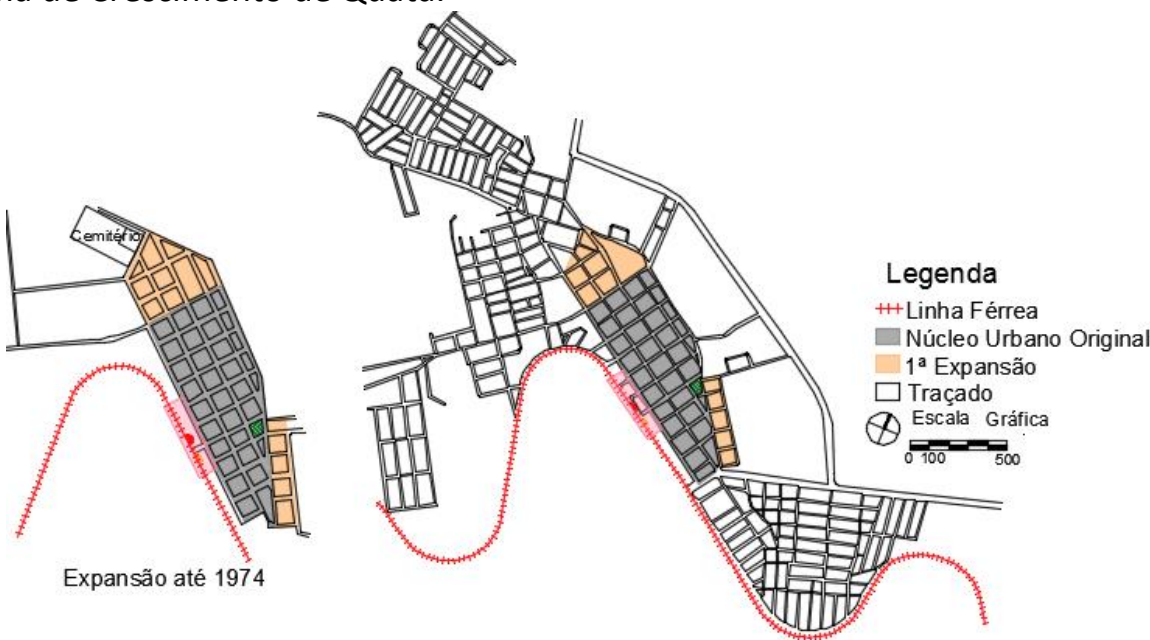

Fonte: Planta Geral de Quatá, 1935, fornecida pelo Arquivo Público do Estado de São Paulo e Planta de Quatá, 2016, fornecida pela Prefeitura Municipal de Quatá, redesenhado pela Autora.

Quatá teve sua esplanada inicialmente ocupada pela estação ferroviária, dois galpões da Estrada de Ferro Sorocabana e as residências de funcionários (Figura 8) e, ainda, localizavam-se próximas à esplanada e à linha férrea, os galpões de indústrias presentes na cidade.

Figura 8. Esplanada de Quatá, 1942.
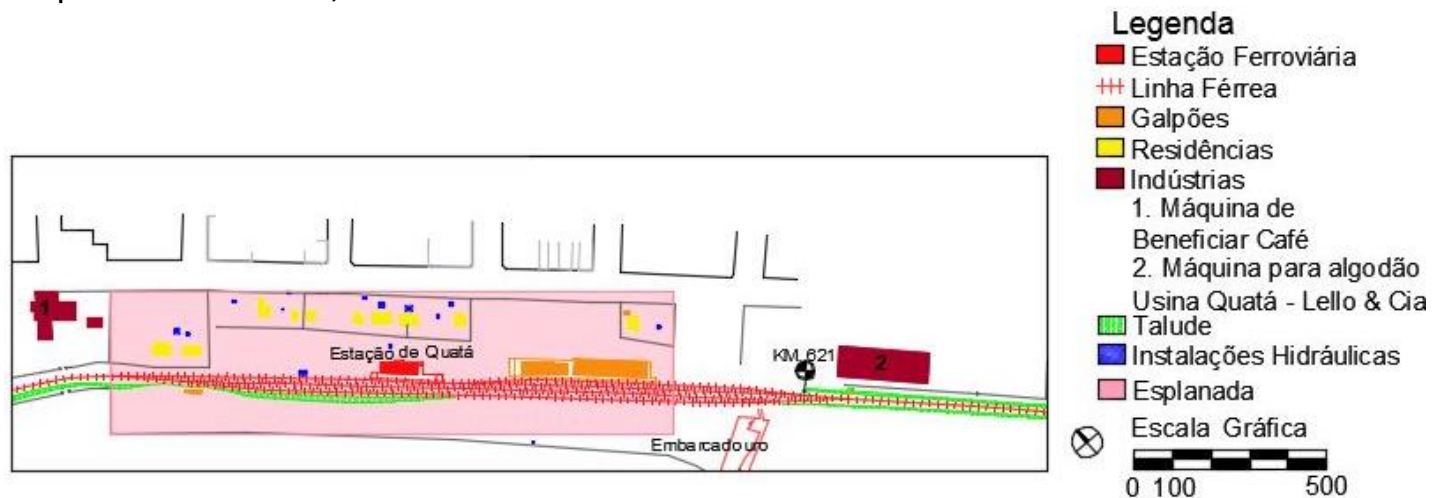

Fonte: Pátio de Quatá, década de 1940, fornecido pelo Escritório da Inventariança da Rede Ferroviária Federal S.A. de São Paulo, redesenhado pela Autora.

A esplanada de Quatá, atualmente, está ocupada por duas praças e residências junto às antigas casas de funcionários da ferrovia, que permaneceram ao longo do tempo, mantendo essas quadras como residenciais (Figura 9).

Figura 9. Mapa da Esplanada de Quatá atualmente.

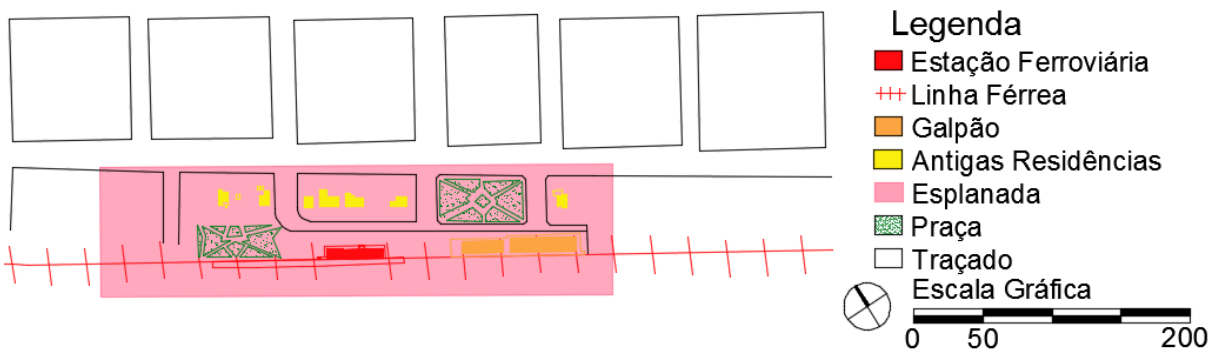

Fonte: Planta de Quatá, 2016, fornecida pela Prefeitura Municipal de Quatá e trabalho de campo, redesenhado pela Autora. 
Em Quatá, "cada quadra continha oito datas de 22 metros de frente, por 44 metros de fundo" (ENCICLOPÉDIA, 2003), resultando em uma dimensão de $88 \times 88$ metros (Figura 10).

Figura 10. Tipologia possível das quadras de Quatá.

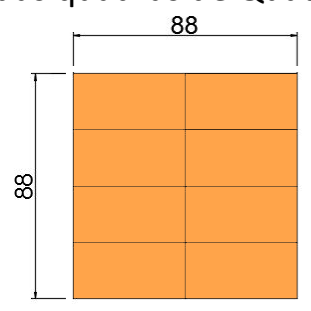

Lotes de $22 \times 44$ metros

Fonte: Planta Geral de Quatá, 1935, fornecida pelo Arquivo Público do Estado de São Paulo e Planta de Quatá, 2016, fornecida pela Prefeitura Municipal de Quatá, analisado e redesenhado pela Autora.

\section{DISCUSSÃO}

A malha ortogonal em tabuleiro de xadrez foi amplamente replicada na região da Alta Sorocabana, devido a sua facilidade de execução e à possibilidade de expansão seguindo o traçado, caso a cidade crescesse. O local de implantação dos trilhos, no espigão dos rios, influenciou a forma desses traçados, já que havia a predominância de terras planas, e a repetição desse desenho era facilitada (CHAVES, 2017; FRANCISCO, 2015).

Paraguaçu Paulista e Quatá possuem essa mesma tipologia de traçado, em tabuleiro xadrez, com quadras de $88 \times 88$ metros. O desenho urbano dessas cidades foi orientado pelos trilhos, estação e esplanada, inexistindo o antigo sistema de formação a partir do patrimônio religioso, ou seja, das terras doadas à Igreja. De acordo com Marx (1991), com a Lei de Terras em 1850, a Igreja vai perdendo seu acesso facilitado a terra, já que esse bem se transforma em mercadoria e a vontade dos proprietários e loteadores é de vende-la.

No entanto, a Igreja Matriz ainda ocupa um importante espaço nessas cidades, localizando-se próximas ao eixo perpendicular da estação. Em Paraguaçu Paulista essa via perpendicular à estação corresponde a uma avenida que se prolonga até a rodovia e funciona como um acesso a cidade, a ocupação da esplanada pela praça não permite que essa avenida chegue diretamente até a estação. Em Quatá, a estação foi implantada no meio de um quarteirão, com a ocupação da esplanada, isso se tornou ainda mais evidente.

As esplanadas dessas cidades apresentam configurações semelhantes, com a presença das residências de funcionários e galpões que, assim como as indústrias, localizavam-se próximos ao trilho do trem, pois utilizavam o transporte ferroviário. Atualmente, em ambas as cidades, as esplanadas foram ocupadas por praças.

A quadrícula foi replicada apenas na expansão inicial nas duas cidades, no crescimento do entorno do núcleo original. No entanto, nos loteamentos mais recentes, esse desenho de traçado não é utilizado, novos modelos de arruamentos são implantados, sendo o inverso do pensamento dos loteadores da continuidade do traçado em tabuleiro em xadrez em áreas de expansões.

\section{CONCLUSÃO}

As cidades de Paraguaçu Paulista e Quatá não são diferentes das demais cidades da Alta Sorocabana, seus traçados iniciais seguem o padrão da malha ortogonal em tabuleiro de xadrez. Na implantação desse tipo de desenho urbano não houve uma preocupação urbanística e estética, o traçado não considerava as condições topográficas do local e se moldava de acordo com os desejos do proprietário das terras e loteador.

Nas cidades estudadas, as edificações principais relacionadas à ferrovia ainda permanecem e são utilizadas de alguma forma, mostrando que há uma certa preocupação com a conservação desses edifícios. Em Paraguaçu Paulista, a estação é usada como sede de uma delegacia e da guarda municipal, os antigos galpões da ferrovia abrigam uma oficina mecânica, uma escola de capoeira e um centro de treinamento de judô, além de um anexo construído para armazenar a Maria Fumaça que realizava os passeios na região. Em Quatá os galpões estão conservados e, em um deles, foi construído o anfiteatro municipal, na estação funciona um centro cultural, com biblioteca e espaço memória, além de a maior parte das residências de funcionários ainda estarem 
conservadas na antiga esplanada, apesar de algumas reformas.

\section{REFERÊNCIAS}

ABREU, D. S. Formação histórica de uma cidade pioneira paulista. Presidente Prudente: Faculdade de Filosofia, Ciências e Letras de Presidente Prudente, 1972.

AMPUDIA. História sobre Paraguaçu Paulista. Disponível em:

<http://ampudia.com.br/paraguacu_historia.htm I >. Acesso em: 07 dez. 2016.

CHAVES, M. G. M. Origem e transformação dos núcleos urbanos das cidades de Martinópolis e Indiana. Colloquium Socialis, Presidente Prudente, v. 1, n. esp., p. 251-259, jan./abr. 2017.

ENCICLOPÉDIA dos Municípios Brasileiros. Presidente Prudente: EMUBRA, 2003. Disponível em $C D$ room.

FRANCISCO, A. M. A EFS como linha de penetração para a ocupação da Alta Sorocabana. 2015. Mimeografado.

Os trilhos da ferrovia: desbravando o território, produzindo cidades na Alta Sorocabana: relatório de pesquisa apresentado ao Conselho Nacional de Pesquisa. Presidente Prudente: Faculdade de Ciências e Tecnologia de Presidente Prudente, Unesp, , 2017. Mimeografado.

GHIRARDELLO, N. A Influência do sistema métrico francês na ortogonalidade das cidades. Revista Educação Gráfica, Bauru, v. 1, n. 1, p. 27-32, 1997.

IBGE, Instituto Brasileiro de Geografia e Estatística. Cidades. Brasília, 2016.

LAMAS, J. Morfologia urbana e desenho da cidade. Lisboa: Fundação Calouste Gulbenkian, 1993.

MARX, M. Cidade no Brasil terra de quem? São Paulo: Nobel; Ed. Universidade de São Paulo, 1991.

PANERAI, P. Análise urbana. Ed. UnB, 2006.

PARAGUAÇU PAULISTA. Prefeitura Municipal.

História. Disponível em: <http://www.eparaguacu.sp.gov.br/historico.asp >. Acesso em: 07 dez. 2016.

QUATÁ. Prefeitura Municipal. História. Disponível em:

<http://www.quata.sp.gov.br/municipio/historia/ >. Acesso em: 07 dez. 2016.

Recebido para publicação em 08/08/2017

Revisado em 15/09/2017

Aceito em 25/09/2017 